\title{
Introduction to the technical and economic analysis of the production process with the use of computer simulation
}

\section{Justyna OGORZAŁEK}

DOI: 10.30464/jmee.2019.3.2.121

Cite this article as:

Ogorzałek J. Introduction to the technical and economic analysis of the production process with the use of computer simulation. Journal of Mechanical and Energy Engineering, Vol. 3(43), No. 2, 2019, pp. 121-130.

\section{VOLUME 3(43) | No. 2 | JUNE 2019}

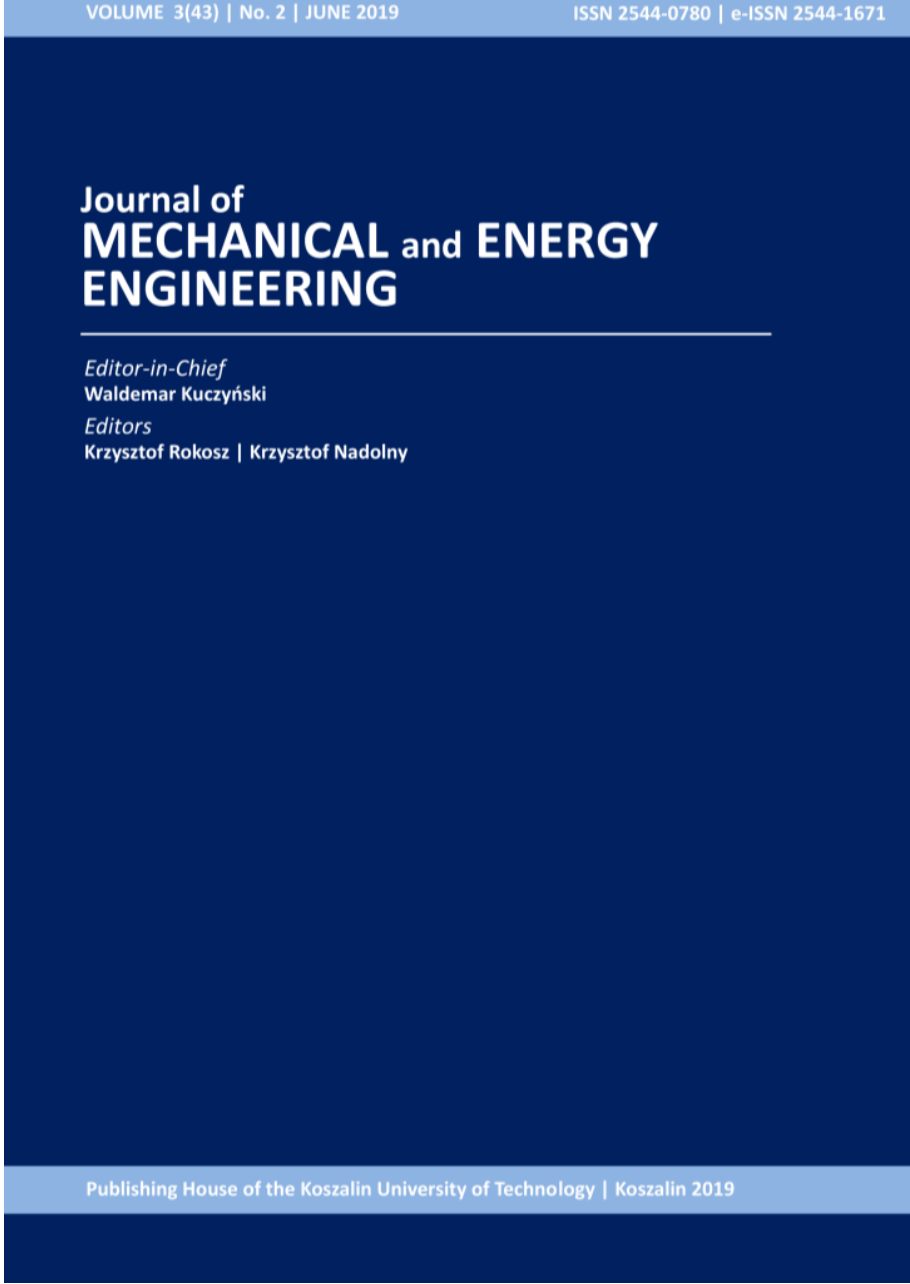

Journal of Mechanical and Energy Engineering

Website: jmee.tu.koszalin.pl

ISSN (Print): 2544-0780

ISSN (Online): 2544-1671

Volume: $3(43)$

Number: 2

Year: 2019

Pages: 121-130

Article Info:

Received 10 April 2019

Accepted 14 May 2019

\section{Open Access}

This article is distributed under the terms of the Creative Commons Attribution 4.0 (CC BY 4.0) International License (http://creativecommons.org/licenses/by/4.0/), which permits unrestricted use, distribution, and reproduction in any medium, provided you give appropriate credit to the original author(s) and the source, provide a link to the Creative Commons license, and indicate if changes were made. 


\title{
INTRODUCTION TO THE TECHNICAL AND ECONOMIC ANALYSIS OF THE PRODUCTION PROCESS WITH THE USE OF COMPUTER SIMULATION
}

\author{
Justyna OGORZAŁEK ${ }^{*}$ \\ ${ }^{1 *}$ Faculty of Mechanical Engineering, Department of Production Engineering, Koszalin University of \\ Technology, Raclawicka 15-17, 75-620 Koszalin, Poland, e-mail: justyna.ogorzalek95@gmail.com
}

(Received 10 April 2019, Accepted 14 May 2019)

\begin{abstract}
The article presents the most important information concerning the methods, techniques and indicators of I measures, which are used in the evaluation of production processes. The theory of limitations, process mapping, benchmarking and diagnostic test method have been described. Sample indicators for the evaluation of production processes are presented and the measures for the evaluation of production processes are discussed, as well as methods of obtaining information about the process. The modelling and computer simulations were described and the algorithm of proceeding during the development of a simulation model was presented. The article discusses system dynamics modelling, discrete event modelling and agent modelling.
\end{abstract}

Keywords: production process, technical-economic analysis, computer simulation, discrete modelling, agent modelling

\section{INTRODUCTION}

Numerical simulations are increasingly used in production processes. The introduction of advanced techniques for the design or improvement of production processes allows the company to reduce the costs that are generated when there is a need for process improvement and when there is a need to work on the real process.

Simulation allows you to reproduce each process, allows you to study and analyze it in detail, and allows you to quickly and financially optimize the process, you can afford many trials and variants in order to select the most appropriate one without incurring costs. Simulation modelling helps to develop costbenefit analyses. With a well-designed model, they can serve as future forecasts for economic analysis.

The article contains the most important issues concerning methods and techniques used in the evaluation of production processes, as well as indicators and measures used in the evaluation of processes. Basics of numerical simulations, their advantages and disadvantages, as well as types of simulation models and their tools are presented.

\section{METHODS AND TECHNIQUES USED IN THE ASSESSMENT OF PRODUCTION PROCESSES}

Enterprises are organizations that produce goods or provide services, and their activities are cooperation between people who use their skills, talents and time. An enterprise is a whole made up of processes which are to create goods for customers [2].

Durlik (1998) defines a process as "a set of activities that transform input elements into output elements representing customer value". Enterprise management is a set of processes that try to satisfy the customer's needs; processes can be divided into [2]:

- basic processes,

- auxiliary processes,

- management processes.

A process mapping technique can be used to identify the process and its components. In order to determine the correct functioning of the enterprise, it 
is necessary to identify and consciously determine the links between the links [2].

The production process can be assessed using various methods and techniques.

\subsection{Theory of Constraints}

Theory of Constraints (TOC) attempts to answer several questions [2].

1. What to change? - Every company has many problems, but limited time, resources and effort do not allow them all to be addressed. The manager should find what needs to be changed in order to improve performance in the company.

2. What to change? - If the most important problems have been found then you have to try to solve them. If you don't use enough effort, it can cause chaos and panic.

3. How to make a change? - The most difficult task is change. In an enterprise, people who work can be reluctant and perceive change as a threat. Changes require a lot of time, capital and effort.

The theory of Constraints assumes that the company is treated as a chain of interconnected units, links in the chain. The whole creates a system whose operation is defined by the weakest link. The "bottleneck" is the weakest link and we must strive to eliminate it. In the theory of limitation, there is also one main objective, which is to make profits now and in the future [2].

There are three categories of limitations [6]:

- physical constraints (bottlenecks), i.e. a resource or resources that limit the achievement of goals in the system,

- policies, i.e. rules and measures that define the way in which the company is managed,

- the paradigms, beliefs, values and attitudes on which enterprise policy is built.

\subsection{Process mapping}

Process mapping is a graphical representation of how the process is carried out, as well as the individual activities carried out in the process. Figure 1 shows an exemplary map of processes from receipt of semi-finished products to storage of the finished product. Relations between activities are also shown. Process maps may present the course of the process, which is the target process, is the desired course of the process and may be a paradigm to the way of introducing improvements and types in the process [5].

Specialized software is used for process mapping, but several methods are also used, such as brainstorming, morphological analysis, or the method of six thought hats [5].

Process mapping consists of the following steps [2].

1. Designing, defining goals.

2. Recognition of the organization's structure.

3. Identification of processes that take place in the organization.
4. Selection of the modelled process.

5. Identification of organizations participating in the process.

6. Analysis of the modeled process.

7. Identification of the workplace.

8. Identification of process discontinuities.

9. Ways to eliminate discontinuities.

10. Checking a new process.

11. Determining the goals of the workplace.

12. Implementation and evaluation of the modelled process.

13. Re-defining the organization's objectives.

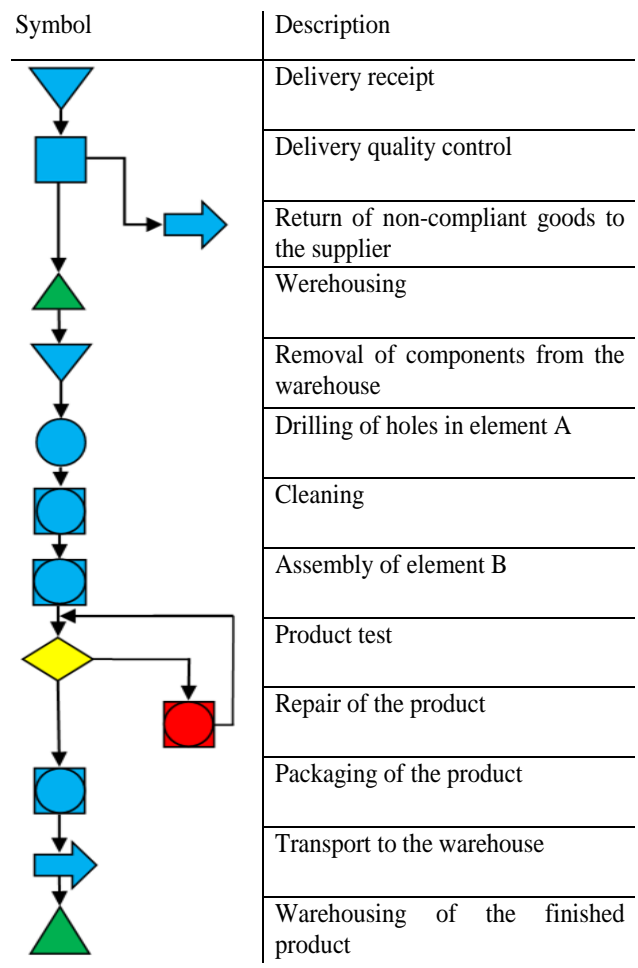

Fig. 1. Example process map [13]

\subsection{Benchmarking}

When solving organizational problems, the philosophy of learning from other organizations, comparing oneself with others, better organizations and copying very good ideas in the face of growing competition is applied, this philosophy is called benchmarking [2].

Benchmarking is one of the few methods that can be applied in solving operational and strategic problems of organizations. It is used to gain competitive advantage through organizational and strategic development. Learning from others and comparing with other organizations is an effective way of solving organizational problems [2].

Each subsequent stage determines qualitative and quantitative indicators on the basis of which the level of process performance is determined. Data is collected for analysis by measuring the values of 
indicators in order to compare them with best practices. Internal benchmarking is used for organizational management and it depends on [2]:

- selecting a team with the best knowledge of the process,

- the environment and the exchange of knowledge and information,

- cultural factors,

- attitudes of leaders.

\subsection{Diagnostic test method}

One of the methods that allows you to evaluate the production process is the diagnostic test method. For the development of the test analysis, reports containing information about the production task performed, as well as information provided by experts from given production cells are used [2].

Diagnostic tests are presented in tables. They may concern [2]:

- production structure,

- analysis of supply and operation of workstations,

- analysis of transport within the plant,

- analysis of technological service,

- analysis of wages of production workers directly,

- analysis of fixed assets.

Table 1 shows an example of a survey form on workstation load.

Table 2 shows a sample survey form for quantitative analysis of the production structure.

Tab. 1. Test form for workstation loading [2]

\begin{tabular}{lcc}
\hline Overloaded machinery and equipment \\
\hline Production section & $\begin{array}{c}\text { Name of the } \\
\text { equipment or } \\
\text { machine }\end{array}$ & $\begin{array}{c}\text { Value of the load } \\
\text { factor [\%] }\end{array}$ \\
\hline
\end{tabular}

\begin{tabular}{ccc} 
Under-loaded machinery and equipment & $\cdots$ \\
\hline Production section & $\begin{array}{c}\text { Name of the } \\
\text { equipment or } \\
\text { machine }\end{array}$ & $\begin{array}{c}\text { Value of the load } \\
\text { factor }[\%]\end{array}$ \\
\hline
\end{tabular}

\section{INDICATORS AND MEASURES FOR THE ASSESSMENT OD PRODUCTION PROCESSES}

Indicators and meters make it possible to quantify the production process. Determination of indicators is used to identify the production subsystem in the organization and the level of correctness of the function of production cells [2].

\subsection{Indicators for evaluation of production processes}

Important indicators for the evaluation of the production process are the indicators described in Table 3. These are classification indicators, factual evaluation indicators and economic evaluation indicators.

In addition to the set of indicators described in Table 3, production efficiency is an important indicator. Efficiency is the ratio of the effect that is achieved to the expenditure incurred. Effectiveness expressed by formula (1) is often converted as a percentage [7]:

$$
E=\frac{e}{n}
$$

where: $E$ - effectiveness; $e$ - effects; $n$ - outlays.

Several ways of increasing effectiveness were distinguished [6]:

- reduction of outlays while maintaining the level of effects (lean production concept),

- reduction of expenditures with increased level of effects (lean production concept, theory of limitations),

- maintenance of expenditure with an increase in the level of effects (agile production concept, restriction theory),

- increase in expenditure with a drastic increase in the level of effects (the concept of agile production, diversification).

The Lean Production concept focuses on reducing inputs (e.g. by reducing costs), a strategy called lean flow, lean production. [7].

The concept of Agile Production, also known as agile manufacturing and agility, is understood here as the fact that the organization of the production system allows the rapid delivery of products tailored to the needs and expectations of customers. This strategy is oriented towards increasing the level of service, is flexible and is able to react quickly to changes in customer and market conditions [11].

The production process is linked to other processes influencing efficiency. Efficiency can be analyzed in different approaches presented in Table 4 [11]. 
Tab. 2. Research form for quantitative analysis of the production structure [2]

\begin{tabular}{ccccc}
\hline Name of the production section & \multicolumn{2}{c}{ Production structure of the production } & Total area $\left[\mathrm{m}^{2}\right]$ \\
\hline \multicolumn{4}{c}{ Lection }
\end{tabular}

Tab. 3. Set of indicators for pre-production analysis [2]

\begin{tabular}{lll}
\hline Lp. Name of indicator & Calculation formula & Notices \\
\hline
\end{tabular}

Classification indicators

$$
W_{1}=\frac{J_{c} \cdot O_{c}}{S}
$$

Indicator of production

1. specialisation (defines the type of production).

where: $J_{c}$ - numer of types parts performer in the examined production section; $O_{c}$ - avarage numer of operaations on one part; $S$-numer of workstations (production machines and devices).
$W_{l}=1-$ mass production,

$W_{l}=\langle 2 ; 10\rangle-$ multiseries production,

$W_{l}=\langle 11 ; 30\rangle-$ serial production,

$W_{1}>30-$ small-scale and oneoff production unique.

$$
W_{2}=\frac{P_{P} \cdot 100}{P_{o}}[\%] ;
$$

2. Coefficient of where: $\mathrm{P}_{\mathrm{P}}$ - labour intensity of repetitive production in a production repeatability. given period; $\mathrm{P}_{\mathrm{o}}-$ labour intensity of total production in the

The indicator can help to same period.

3. Production rhythmicity indicator. - production volume of a given period in the units adopted; $\mathrm{P}_{\mathrm{m}}-$ monthly production volume in the same units.
This indicator is determined by production characteristics (type of production, length of production cycles, type of

\begin{tabular}{|c|c|c|c|}
\hline 4. & $\begin{array}{l}\text { Machinery and } \\
\text { equipment utilisation } \\
\text { rate. }\end{array}$ & $\begin{array}{c}W_{4}=W_{t} \cdot W_{z} ; \\
\text { where: } \mathrm{W}_{\mathrm{t}}, \mathrm{W}_{\mathrm{z}}-\text { indicators of extensive and intensive use of } \\
\text { machinery. }\end{array}$ & $\begin{array}{l}\qquad W_{t}=\frac{T_{f}}{T_{d}} ; \\
\text { where: } T_{f}, T_{d}-\text { actually worked } \\
\text { and available (means reduced } \\
\text { by the time of planned repairs } \\
\text { and maintenance) working time } \\
\text { of machines and devices; } \\
\qquad W_{z}=\frac{Z_{t}}{Z_{p}} ; \\
\text { where: } Z_{t}, Z_{p}-\text { actual and } \\
\text { planned production capacity } \\
\text { expressed in natural units. }\end{array}$ \\
\hline 5. & $\begin{array}{l}\text { Cost of } 1 \mathrm{~m}^{2} \text { of usable } \\
\text { area. }\end{array}$ & $\begin{array}{c}\qquad W_{5}=\frac{S_{t}}{P} \\
\text { where: } \mathrm{S}_{\mathrm{t}}-\text { value of fixed assets of production; } \mathrm{P}-\text { usable } \\
\text { area. }\end{array}$ & $\frac{z \nmid}{m^{2}}$ \\
\hline
\end{tabular}
production). 
Tab. 4. Selected approaches to production [7]

\begin{tabular}{ll}
\hline Efficiency & Characteristics \\
\hline Operational & $\begin{array}{l}\text { It concerns the reduction of costs, } \\
\text { reduction of losses and shortening of } \\
\text { production cycles. }\end{array}$ \\
\hline Marketable & $\begin{array}{l}\text { It is defined by distinguishing elements, } \\
\text { the analysis of which serves to assess } \\
\text { the effectiveness of e.g. the product, } \\
\text { costs, market share. }\end{array}$ \\
\hline According to profit & $\begin{array}{l}\text { Determined by the maximization of } \\
\text { profit in the company. }\end{array}$ \\
\hline Techiterion & $\begin{array}{l}\text { Occurs when you cannot increase the } \\
\text { level of one of the results without } \\
\text { reducing the level of another result at } \\
\text { the same time. }\end{array}$ \\
\hline Dynamic & $\begin{array}{l}\text { Used to measure the pace of } \\
\text { development of new products, market } \\
\text { penetration, new technologies and } \\
\text { skills. }\end{array}$ \\
\hline
\end{tabular}

\subsection{Measuring instruments for evaluation of} production processes

There are three production meters [2].

1. Value measures - their feature is to attribute a monetary expression to costs incurred while conducting business activity and are expressed in any currency.

2. Quantitative meters - three meters are distinguished:

- natural - used in homogeneous production,

- typical product - a product which influences the image of the company, and simultaneously manufactured products are converted into typical products by means of various factors (weight, quality),

- conventional product - a fictitious product, which may appear temporarily.

3. Labour-intensive meters - they express the amount of living work, which is incurred during the processes.

\subsection{Methods of obtaining information on the production process}

Information according to the Alien Words Dictionary is a notification, a message, a place where information on a particular subject is provided.

Quantitative (indicative) and quantitative (sociological and descriptive) techniques are used to identify the parameters of a production process evaluation system and to obtain information about the system [2].

Indicative techniques include [2]:

- indicators of the level and dynamics of phenomena,

- structures,

- intensities,

- evaluation of efficiency and effectiveness,

- disruptions,

- deviations.
However, quality techniques are used for this purpose:

- surveys,

- interviews,

- a verbal description,

- diagnostic tests.

\section{BASICS FOR THE SYMULATION OF COMPUTER PRODUCTION PROCESSES}

Modelling is a way to solve real problems, but often real objects cannot be allowed to be experimented with. One of the simpler and generally available modeling tools is Microsoft Excel, which has several advantages: it is very easy to use, widely available and allows you to add scripts to formulas. Spreadsheets-based modeling is simple - you can enter data into cells, while others display the output. Very complex models also allow you to optimize your data. Spreadsheets are used for scheduling, loading or unloading, or to determine delivery times [4].

Simulations and modelling are used when it is difficult to obtain a solution with analytical methods, and experiments on a physical model are too expensive and time-consuming. Simulations make it possible to trace and analyse the production process. They are also used to verify certain assumptions, which also allows to detect irregularities [1].

Simulations and modelling of the production process is based on the creation of a virtual computer model, which shows the real production system. During the simulation, various types of reports are obtained, which allow you to develop further actions or improvements to the production process. The model can be improved by adding new machines, stations, warehouses and their capacity, which allows for further simulations and their verification [1].

Computer simulation models contain logic in their structure, which presents the behavior and mutual relations of individual components of the system. The functioning of the system can be presented graphically using animation. Modelling of production systems comes down to determining their characteristics consist of many unrelated or cooperating processes, and each process is defined as a sequence of activities [8].

The simulation of the production system makes it possible to analyze alternative variants of processes and is also a good tool for evaluating new technological solutions.

In order to build a simulation process model, many stages are needed, as shown in Figure 2. 


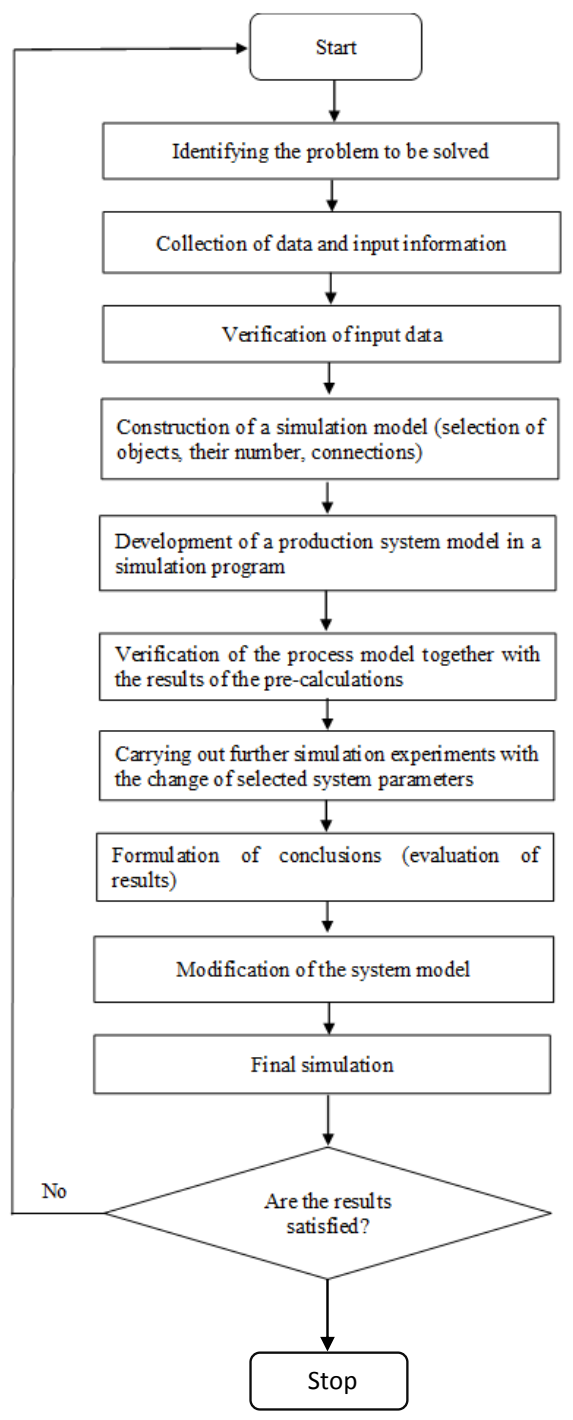

Fig. 2. Algorithm of procedures for the development of a simulation model of the production process [1]

The use of simulation enables the integration of production preparation processes, as well as the production itself. It also makes it possible to optimize information processes. Simulation also helps to make decisions at different levels of management, it also becomes an important tool for planning processes taking place in the company [8].

Three types of simulation models are distinguished, which are distinguished on the basis of the description of variables [8]:

- continuous - the state change is continuous, the passage of time is described as a continuous function,

- discreet - the change of state is discreet, the passage of time is described by discreet function,

- mixed (hybrid) - the change of state is continuous discrete, the passage of time is described as continuous, discrete or pseudo-pulse function.
The Table 5 shows the advantages and disadvantages of simulation methods.

Tab. 5. Advantages and disadvantages of simulation methods

\begin{tabular}{|c|c|}
\hline $\begin{array}{l}\text { Advantages of simulation } \\
\text { methods }\end{array}$ & $\begin{array}{l}\text { Disadvantages of simulation } \\
\text { methods }\end{array}$ \\
\hline 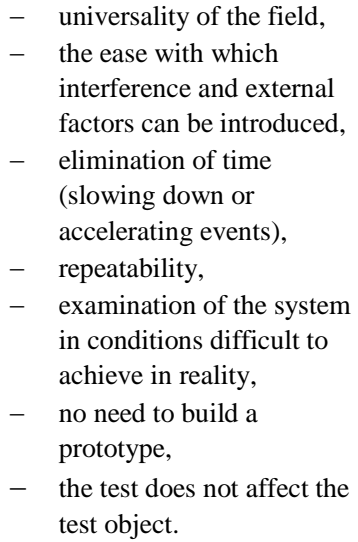 & 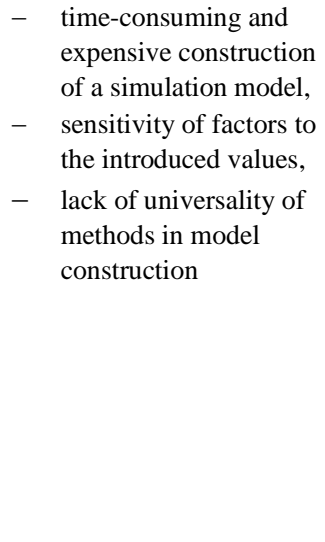 \\
\hline
\end{tabular}

\section{MODELLING THE DYNAMICS OF SYSTEMS}

System Dynamics (DS) is a continuous simulation and, compared to discrete, periodic processes, it is distinguished by the fact that it takes place in fixed conditions in which raw materials are delivered and received simultaneously in an uninterrupted manner [6].

The method of system dynamics is based on several assumptions [8]:

- continuity - continuous functions are used to describe changes in the state of the system,

- dynamic orientation - the aim is to study the dynamic properties of the system,

- causality-causal - effect relationships are used,

- periodicity of regulatory activities - they are periodical in nature.

- the structural elements of the models in the dynamics of the systems are the resource (level) and stream (flow). There are also auxiliary variables, constants, functions and relationships [8].

A resource is a quantity, it determines the quantitative state. If this value is variable in the model, then the concept of stream is also applied and it defines the resource in the considered period of time. The resource is related to input and output streams [8].

The state of the system in a continuous simulation is a system of differential equations as a function of the simulated time. An example of continuous simulation can be a simulation of physical phenomena, e.g. changes in weather or gas flow around a rigid mass. The first continuous simulations were carried out using analogue machines [9].

In the dynamics of systems there are several tools that model the process [8]. 
1. DYNAMO modelling language. This is the first language of continuous simulation modelling, it has a graphical interface. Fixed values and variables are described by names that contain from one to five characters. The DYNAMO language allows you to print the results in the form of tables and diagrams.

2. IThink/Stella modeling system. This system belongs to the integrated modeling systems, has additional functions such as model map, editing equations, model validation, conducting experiments, defining the form and structure of output objects.

3. Vensim modeling system. It is a modeling environment with a graphical interface and the possibility of statistical estimation.

4. Powersim modelling system. It allows to create an integrated and efficient environment with a graphical interface.

\section{MODELLING OF DISCRETE EVENTS}

Discrete simulation is a simulation in which system state variables change discretely. Time elapses through the sequence of events. Modelling in a discrete simulation is object-oriented modelling or modelling with the help of a network of activities. Network models are Petri networks as well as evaluation networks [8].

The discrete simulation model has the following constructional elements [8]:

- system clock - registers the real time of the system, it is a dynamic object,

- system calendar - contains the system clock, as well as a collection of information about events, it is a dynamic object,

- system resources are static objects.

Discrete simulation is based on several assumptions [8]:

- object orientation - the system is described by dynamic and static elements of the system,

- individualization of objects in the system - each object is separately identified, creates classes, sets or attributes,

- discretion of state changes in the system description of changes in system states takes place by means of discrete functions,

- discrete time of observation of states in the system - time changes by means of the method of sequelae of events,

- statistical property orientation - the results of the simulation are the combined characteristics of the system,

- orientation on events, activities and processes the basis of simulation is the physical course of events, which creates activities and processes.
During the experiment, it is necessary to introduce uncertainty and randomness of the system. Then random values are introduced into the model, according to a certain probability distribution, using the Monte Carlo method. Application of the method consists of the following steps [8].

1. Selection of random variables (probability distribution).

2. Selection of input variables.

3. Calculation of several observations, generation of random variables, determination of output variables, repetition of observations in the sample, determination of parameters of output statistics.

4. Performing calculations.

\subsection{Discrete modelling methods}

There are three methods of discrete modelling [8].

1. Event planning - an object called "calendar of events" is used, only unconditional, timedependent events are introduced there. Next, subsequent events are defined, activities related to the occurrence of events are introduced, the simulation is controlled based on the calendar of events. Entering events has the character of planning times, types and parameters of unconditional events.

2. Review and selection of actions - system actions are considered and it is determined which of them should be started and which should be completed at the moment of the event. This means that events are first entered into the calendar, then activities related to conditional events are considered, and the simulation is controlled by means of a list of conditions. Events are entered by checking the condition list cyclically.

3. Process interaction - this is a combination of an event planning method and the review and selection of actions

\subsection{Modelling tools}

There are several modelling tools in discrete simulation. These include [8]:

- GPSS (General Purpose Simulation System) modelling language - it is a simulation programming language which has process orientation. The language has elements such as objects, commands, programming blocks and predefined variables SNA.

- ExtendSim modeling system - with the help of this system it is possible to build models that are process-, event- or process- and event-oriented.

- Arena modeling system - it is an integrated software for modeling and simulation, this system has universal elements for describing any systems. Arena helps to model and simulate processes with different levels of complexity. Its basic functions include modeling, simulation, visualization and analysis. 


\section{AGENT MODELLING}

Agent modelling is currently used in many areas, among others in economics, management, technical and social fields. An agent can be a person, device, machine or software that performs a specific activity [8].

Agent modelling has been created because of technological progress, which allowed to apply new methods of object-oriented modelling thanks to computer science. Faster processors and larger memory have also been introduced to the market, and agent-based models are more demanding than system dynamics or discrete event modelling [4].

Agents in agent modeling can take the form of e.g. Vehicles, equipment, products, organization, investments, ideas, and even people in different roles [4].

An agent in information technology is a computer system that is placed in the environment and is able to react in the environment to perform specific actions. The agent system should have several specific properties [8]:

- autonomy - the agent himself chooses the plan according to which he will act, he does it using artificial intelligence or fuzzy logic,

- reactivity - the agent analyses changes in the environment and reacts to them,

- adaptability - the agent is able to adapt to changes taking place in his environment, it does so thanks to the experience gained in the analysis process,

- business continuity - the agent learns continuously by interacting with the user or other agents,

- purposefulness of action - the agent strives to achieve the set goal,

- openness - an agent is a system that is open in interaction and communication with another system,

- ability to cooperate - the agent cooperates with other agents in order to achieve the set goal,

- mobility - the agent can move between different points in the network,

- possibility of inference - the agent stores knowledge, thus learning and making decisions,

- limited rationality - the agent works optimally,

- anthropomorphism and personification - the agent can be assigned certain physical features of a person.

Agent technology is used in anthropomorphic systems, e.g. as virtual teachers, salesmen, actors in computer games [8].

In order to build an agent system, an appropriate platform is needed, which should provide an agent management system. Artificial intelligence systems are used to support agent systems, which are based on inference rules, neural networks and genetic algorithms [8].

\section{SELECTION OF SOFTWARE FOR MODELLING AND SIMULATION OF PRODUCTION PROCESSES}

Simulation programs develop almost continuously because of the high demand for them. It is important to select the right program for the processes in the company that will be simulated [12].

Most of the simulation packages use VIMS (Visual Interaktive Modelling Systems) technique, which allows to build a simulation model in a visual and interactive way. The user of such a system does not need to know the programming language, as all parameters and settings are made with the help of menu functions [12].

There are many simulation programs and they include AutoMod, Arena, ROBOCAD, Simple++, Factoryflow, IThink Analyst, ProModel, AnyLogic. These are the best-known programs and do not exhaust the full list of software used for simulation [12].

The most important point in the selection of software is to define the type of system to be modeled, as well as to determine whether modeling is to be simple, fast and superficial, or perhaps complex and detailed. It is also necessary to take into account the finances of the enterprise, as well as the ability of the employees to use the software. The next step is to draw up a list of criteria and compare simulation packages. Criteria can be [12]:

- manufacturer's warranty and support (possibility of consultation, offering training, availability of technical support, quality of documentation, foreign language versions),

- hardware and software requirements (cooperation with operating systems, Internet access),

- creation and testing of the model (ease of model construction, possibility of creating documentation, existence of a testing and error checking option),

- entering data and the possibility of their analysis,

- an internal programming language,

- reporting and analysis of input data,

- experimental planning (operational control),

- cost (selling price, maintenance costs, technical support costs, training costs).

It is worth determining the weight for each criterion and on this basis analyse each of the packages in order to obtain a numerical evaluation of the package, which will allow the purchase of appropriate software for the enterprise [12].

\section{SUMMARY AND CONCLUSIONS}

The presented analysis provides the most important and basic information concerning the methods and techniques used in the evaluation of production processes, indicators and measures for the evaluation of production processes and contains 
information on numerical simulations of production processes.

On the basis of the cited analyses, the following conclusions have been formulated.

1. The production process can be evaluated by means of many different methods and techniques, which often use block diagrams, graphic and tabular forms, and can be evaluated by means of indicators and quantitative measures.

2. By using methods and techniques, many process limitations, such as bottlenecks, can be found, and production processes can be improved and organizational problems can be solved.

3. Indicators and measures of evaluation of production processes make it possible to evaluate the production process in a numerical way, show whether it is necessary to increase production, add a working shift, hire an additional employee or buy a new machine.

4. Computer simulations allow for the creation of a virtual enterprise, its analysis, error detection, also allow for process optimization, which may later affect the efficiency of the enterprise. However, simulation models are not universal and must be adapted to each environment.

5. Computer simulations help in the analysis of alternative variants of production processes, which allows to choose the most advantageous one.

\section{References}

1. Ciszak O. (2007). Computer-aided modelling and simulation of production processes, Scientific Papers oft he Poznań University of Technology, No. 3 (in Polish).

2. Dohn K. (2006). Study of production process evaluation in a industrial enterprise, Wydawnictwo Politechniki Śląskiej (in Polish).

3. Durlik I. (1998). Restructuring of economic processes reengineering - theory and practice, Agencja Wydawnicza "Placet" (in Polish)

4. Grigoryev I. (2016). AnyLogic in three days, 7-10, 21-23.

5. Hofman M., E. Skrzypek E. (2010). Process management in the company, Wolters Kluwer Polska Sp. z o.o., 76-77 (in Polish).

6. Knosala R. (2017). Production engineering. Compendium of knowledge, Polskie Wydawnictwo Ekonomiczne S.A, 789-790 (in Polish).

7. Kotliński A. (2011), Logistics, No. 5/2011.

8. Kukla S., Maciąg A., Pietroń R. (2013). Forecasting and simulation in the company, Polskie Wydawnictwo Ekonomiczne, 148-149, 173, 183-187, 197-198, 202209, 214, 216 -218, 220, 223-224, 231, 236, 277-278, 283, 296-297 (in Polish).

9. Łatuszyńska M. (2011). Computer simulation methods logical classinfication test, Studies \& Proceedings of Polish Association for Knowledge Management, $\mathrm{nr} 41$, 168-170 (in Polish).

10. Siciak P. (2002). Approach deliberately, Magazyn Kadry Zarządzającej, 3 (in Polish).

11. Włodarkiewicz-Klimek H. (2016). Concept and models of agile company, Zeszyty Naukowe Politechniki Poznańskiej, nr 71, 214 (in Polish).
12. Zdanowicz R. (2006). Selection of software for modeling and simulation of manufacturing processes, Pomiary Automatyka Robotyka, nr 1, 10-14 (in Polish).

13. www.governica.com (access: January 2019).

\section{Biographical note}

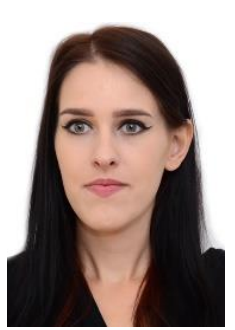

Justyna Ogorzalek received a diploma of enginee in 2018 at the Faculty of Mechanical Engineering of Koszalin University of Technology, faculty of Management and Production Engineering, specializing in Computer Technology in Production Engineering. Her scientific interested focus on the optimization of production processess using numerical simulation. During studies she was twice awarded a scholarship and was a member of the LogTech scientific society. She currently works at Meden-Inmed as a constructor. 
